\title{
The interaction between local factors and the Convectively Coupled Equatorial Waves over Indonesia during the Western North Pacific and Australian monsoon phase
}

\section{Ida Pramuwardani (D)*, Hartono, Sunarto}

Faculty of Geography, Gadjah Mada University, Sekip Utara, Bulaksumur, Yogyakarta 55281, Indonesia, e-mail: idapramuwardani@gmail.com

*Meteorological Climatological and Geophysical Agency, Jl. Angkasa I No. 2 Kemayoran, Jakarta Pusat, DKI Jakarta 10720, Indonesia DOI: $10.26491 / \mathrm{mhwm} / 117576$

ABSTRACT. A large scale perturbation by the Convectively Coupled Equatorial Waves (CCEW) is often observed in the tropics as a precursor to influence weather condition, for example over the Indonesian archipelago (Maritime Continent (MC)). This study examines the interaction between local factors and CCEW with regard to convection and vertical interferences on a local scale over Indonesia during extreme Western North Pacific (WNP) and Australian (AU) monsoon phases. Through space-time spectra analysis of a 15 year (2001-2015) Tropical Rainfall Measuring Mission (TRMM) 3B42 dataset, the propagation of CCEW, i.e. Kelvin, Equatorial Rossby (ER) and Mixing Rossby-Gravity (MRG) waves was assessed. An Empirical Orthogonal Function (EOF) 1 and 2 for each wave evolution across the region of Indonesia, was then compared with daily precipitation anomalies and multilevel wind observations from seven locations in Indonesia to assess the interaction between local factors and CCEW. Results suggest there is evidence of local convection associated with Kelvin waves in the afternoon through to the evening in Tangerang, Surabaya and Makassar during WNP monsoon phases. Local convection associated with MRG waves only occurred in Makassar at the last evolution day during the same period, while there is no clear evidence for an interaction between local factors for ER waves. Low-level westerly winds appear to be significantly coupled with convection from Kelvin waves in Tangerang, Surabaya, and Makassar during the WNP monsoon phase, while the interaction is less significant for MRG-coupled convections (except in Makassar during the same monsoon phase) and absent for ER waves. This study suggests that the global scale phenomena of the Kelvin wave is associated with local scale factors in controlling convection, particularly during an extreme WNP phase in Indonesia.

KEYWORDS: Convectively Coupled Equatorial Waves, Kelvin wave, local factor, monsoon, Indonesia. 


\section{INTRODUCTION}

Since its discovery by Yanai and Maruyama (1996), tropical equatorial waves have emerged as a popular research topic when investigating the significant drivers of regional weather dynamics (Liebmann, Hendon 1990; Takayabu, Nitta 1993; Wheeler, Kiladis 1999; Lubis, Jacobi 2014). Further study linked this phenomenon with convective activity (Wheeler, Kiladis 1999), described as Convectively Coupled Equatorial Waves (CCEW). Using spacetime spectra analysis (hereafter referred to as WK99) to filter long periods of time series data, each type of wave can be distinguished by its wavenumber and frequency; i.e. Kelvin, Equatorial Rossby (ER), Mixing Rossby Gravity Wave (MRG), and Inertia Gravity (IG). When a wave is coupled with convection, CCEW can modulate rainfall variability in the tropics, particularly over the Maritime Continent (MC) of Indonesia (Wheeler, McBride 2005; Kiladis et al. 2009; Horinouchi 2012; Lubis, Jacobi 2014). Furthermore, the Asian-Australian monsoon plays a significant role for CCEW behavior over the MC, as it can intensify and shift the impacted area latitudinally (parallel to the equator) (Wheeler, McBride 2005; Kiladis et al. 2009; Horinouchi 2012; Lubis, Jacobi 2014). Additional interactions between the Madden-Julian Oscillation (MJO) and CCEW over the MC, as well as local factors such as regional terrain complexity cause further complicate regional rainfall variability and weather patterns (Kikuchi et al. 2017).

The aim of this study is to investigate the contribution of local factors in comparison with convective and vertical influences at a local scale, to help constrain global CCEW phenomena during the Asian and Australian monsoon phase over Indonesia. In this study, the Asian monsoon phase, represented by the Western North Pacific (WNP) monsoon, and the Australian (AU) monsoon phase are defined by the global rainfall monsoon domains described by Wang et al. (2012) (Fig. 1).

\section{DATA AND METHODS}

The Tropical Rainfall Measuring Mission (TRMM) $3 \mathrm{~B} 42$ version 7 (V7) is a combined precipitation estimation from multiple satellites which has been proven as an adequate proxy for precipitation for tropical areas related to the Asian-Australian monsoon (Giarno et al. 2018). The daily precipitation from a 15-year dataset (2001-2015) of 3B42 was used to filter Kelvin, ER, and MRG waves using space-time spectra analysis WK99. This method transforms a space-time 3B42 dataset into a wavenumber-frequency form, which then filters each wave based on each specific wavenumber and frequency domain according to each wave characteristic (Wheeler, Kiladis 1999). Using a 30 year
850 hPa zonal wind dataset (1986-2015) from the ERA-Interim reanalysis, days of extreme monsoon activity were identified, based on the expected variability characterized by the WNP and AU monsoon indices from Wang and Fan (1999) and Yim et al (2013). WNP and AU indices were calculated by averaging low-level zonal wind; WNP index was from $\mathrm{U} 850\left(5^{\circ} \mathrm{N}-15^{\circ} \mathrm{N}, 100^{\circ} \mathrm{E}-130^{\circ} \mathrm{E}\right)-\mathrm{U} 850$ $\left(20^{\circ} \mathrm{N}-35^{\circ} \mathrm{N}, 110^{\circ} \mathrm{E}-140^{\circ} \mathrm{E}\right)$, whereas AU index was calculated from U850 $\left(0^{\circ} \mathrm{S}-15^{\circ} \mathrm{S}, 90^{\circ} \mathrm{E}\right.$ $\left.-130^{\circ} \mathrm{E}\right)-\mathrm{U} 850\left(20^{\circ} \mathrm{S}-30^{\circ} \mathrm{S}, 100^{\circ} \mathrm{E}-140^{\circ} \mathrm{E}\right)$. The days with extreme WNP and AU monsoon indices were collated to define the three months with the most extreme monsoon index over Indonesia. Since monsoon phases are commonly referred to by the season with prevailing winds (cf. Ramage 1971) rather than by its peak monsoon index, the WNP monsoon phase will be referred to as December-January-February (DJF), while the $\mathrm{AU}$ monsoon phase will be referred to as July-August-September (JAS).

Adapted from the method of Zhao et al. (2013), an Empirical Orthogonal Function (EOF) mode 1 and 2 was applied to each filtered wave to determine its evolution stage, obtained using a lag-regression method. Furthermore, significant CCEW in the $3 \mathrm{~B} 42$ dataset were identified using Principal Component (PC) 1 and 2 above the standard deviation. Days of both significant CCEW and extreme WNP and AU monsoon activity were then collated to form a group of days with extreme WNP and AU monsoon phase related to CCEW. Through spatial analysis of these groups of data from EOF 1 and 2, the mode with the most similar wave variance was identified, where Kelvin was represented by EOF 2, while ER and MRG were represented by EOF1. Through this method, the evolution stage of CCEW related to extreme NWP and $\mathrm{AU}$ monsoon phases was obtained.

Furthermore, using a 30 year (1986-2015) observation dataset of daily precipitation from seven stations (Fig. 2), normal rainfall variability was determined. Using 3 hour time-steps, precipitation anomalies outside of this normal variability which occurred in WNP and AU monsoon phases in the same dataset during the most recent 15 years (2001-2015) were then plotted for each wave evolution stage related to CCEW, to represent the local precipitation characteristic in the seven locations over Indonesia (Fig. 2). Additionally, days with an average of 12-hourly multi-level winds which occurred within the same period, as observed from sounding stations within similar locations, were plotted to demonstrate local atmospheric dynamics related to CCEW. This multi-level wind dataset was obtained from the Indonesian Agency of Meteorology Climatology and Geophysics (BMKG).

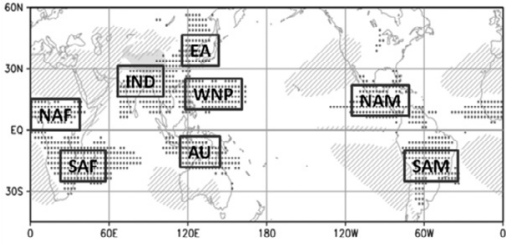

Fig. 1. Regional precipitation domains defined and abbreviated by Wang et al. (2012); this study focusses on the Western North Pacific (WNP) and Australian (AU) monsoon phases

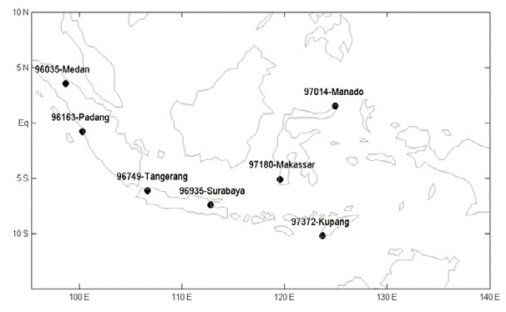

Fig. 2. Observational sounding stations from the Indonesian Agency of Meteorology Climatology and Geophysics (BMKG) dataset, identified by WMO number and city name

\section{RESULTS AND DISCUSSION}

The spatial distribution of each CCEW evolution stage is overlaid with the average daily precipitation in Figures 3, 4 and 5 (for Kelvin, ER, and MRG waves, respectively). These figures indicate that precipitation generally follows the location of the wave perturbation, particularly for Kelvin waves (Wheeler and McBride 2005). Figure 3 also shows a strong link between a positive Kelvin wave and heavy precipitation over the Indonesian region during both extreme monsoon phases. Therefore suggesting that Kelvin waves are adequate to control weather conditions in Indonesia during an extreme WNP and $\mathrm{AU}$ monsoon phase. Meanwhile, ER waves appear to be less vigorous than Kelvin and display unorganized disturbance patterns, presumably due to its off-equatorial impact (cf. Matsuno 1966; Kiladis, Wheeler 1995; Kiladis et al. 2009; Lubis, Jacobi 2014), where maximum perturbations occur in regions to the north and south of the equatorial line, but still within tropical latitudinal boundaries. Although the effect of ER waves is less strong than Kelvin, there are some positive ER signals that could potentially be associated with the intensification of precipitation in Indonesia during both extreme monsoon phases, particularly over Papua at day -4 during DJF and over western offshore of South Sumatra at day 0 during JAS. Meanwhile, lower magnitude perturbations of MRG waves were observed over Indonesia compared to Kelvin and ER, in line with the previous study of Kiladis et al. (2009), therefore indicating that MRG waves are inadequate to evoke extreme precipitation over 

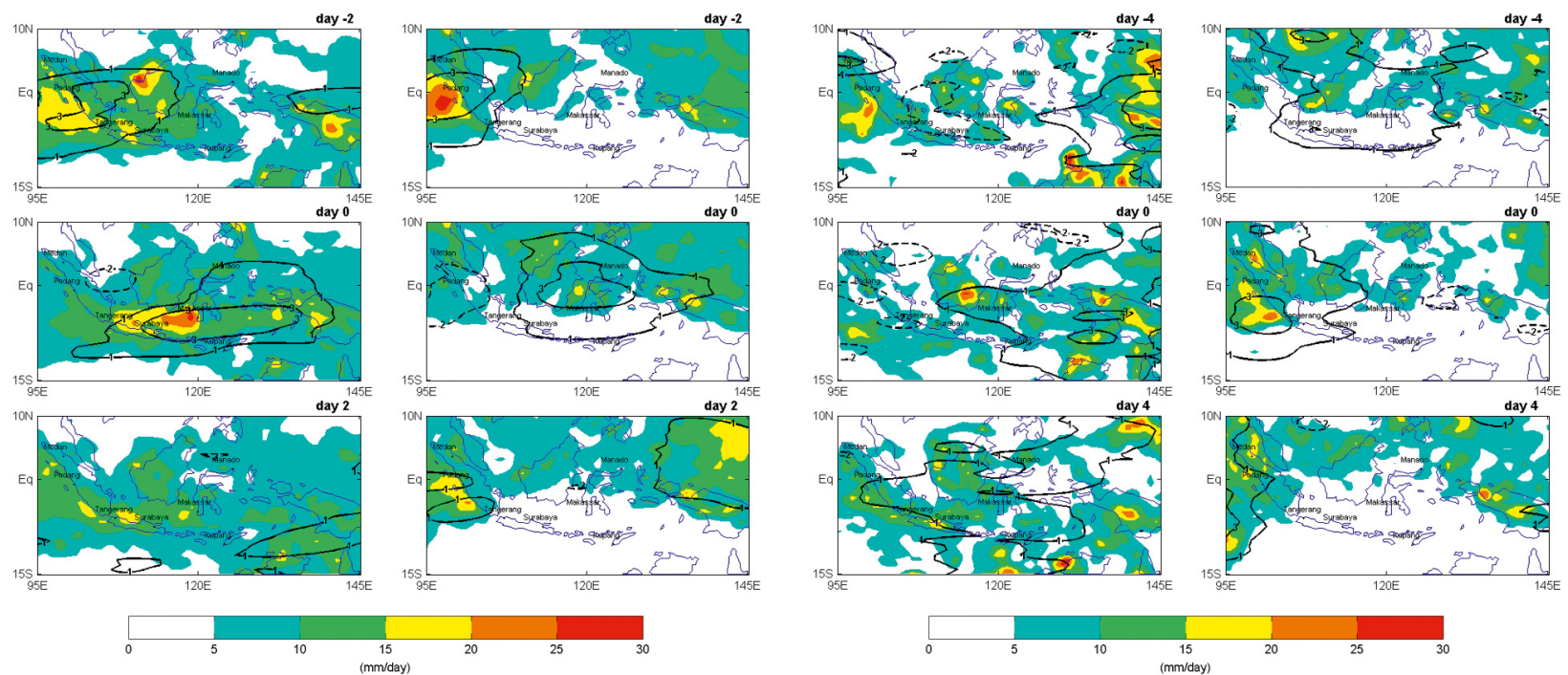

Fig. 3. Day -2 through day +2 lags of Kelvin wave propagation associated with daily precipitation rate (colored shades; $\mathrm{mm} /$ day). Kelvin wave propagation is represented by EOF2 using lag-correlation of EOF1 and 2 from 15-year Kelvin-filtered TRMM-3B42 (solid black contour lines for positive and dashed black contour lines for negative), for DJF-WNP (left) and JAS-AU (right) monsoon phase over Indonesia
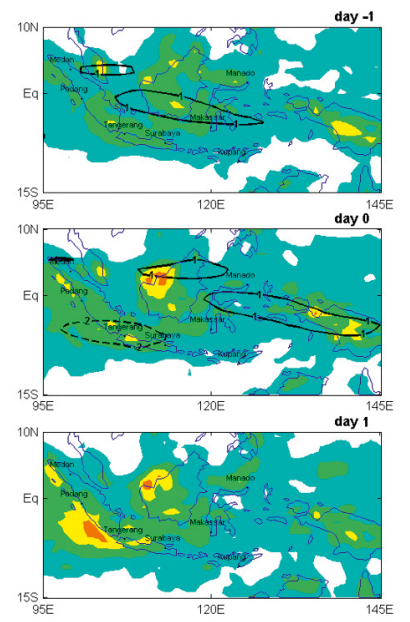

Fig. 4. Day -4 through day +4 lags of ER wave propagation associated with daily precipitation rate (colored shades; $\mathrm{mm} / \mathrm{day}$ ). ER wave propagation is represented by EOF1 using lag-correlation of EOF1 and 2 from 15-year Kelvin-filtered TRMM-3B42 (solid black contour lines for positive and dashed black contour lines for negative), for DJF-WNP (left) and JAS-AU (right) monsoon phase over Indonesia
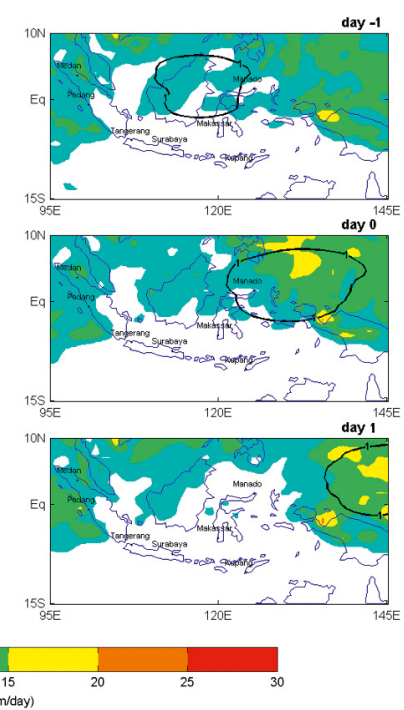

Fig. 5. Day -1 through day +1 lags of MRG wave propagation associated with daily precipitation rate (colored shades; mm/day); MRG wave propagation is represented by EOF1 using lag-correlation of EOF1 and 2 from 15-year Kelvin-filtered TRMM-3B42 (solid black contour lines for positive and dashed black contour lines for negative), for DJF-WNP (left) and JAS-AU (right) monsoon phase over Indonesia

this region. However, considerable precipitation which overlaps with positive MRG perturbation from day 0 to day 1 over Kalimantan and Papua during DJF, confirms that MRG waves contribute to intensifying convection, even though the impact on precipitation is less significant compared with Kelvin and ER waves.

Even though there is a northward and southward shift in precipitation as a result of solar insolation during an extreme AU and WNP monsoon phase, the areas affected are still limited regions near the equator as a result of the dynamic constraints around the equatorial line (Wheeler, Kiladis, 1999). However, Kelvin and MRG waves were more confined to equatorial regions (cf. Matsuno 1966; Gill 1982) compared with ER waves which extended further latitudinally into the northern and southern hemisphere. Moreover, there is a slight discrepancy in the latitudinal distribution between an extreme DJF-WNP and JAS-AU monsoon phases, where the extent of DJF appears to be closer to the equator (Indonesia-Malaysia region) than JAS which spreads northward. This pattern is presumably caused by the increased abundance of water vapor over the Indonesia-Malaysia region during DJF which is absent during JAS (Ramage 1971), enhancing convection significantly over equatorial MC during DJF. Further examination is needed to clarify this relationship.

Figure 6, 7 and 8 show a diurnal cycle (with 3 hour time-steps) of precipitation anomalies for each wave evolution stage during WNP and AU monsoon phases (as in Fig. 3-5). Positive precipitation anomalies, particularly during day 0 (Fig. 6; left), suggests a positive feedback of Kelvin waves on local precipitation in Indonesia during 

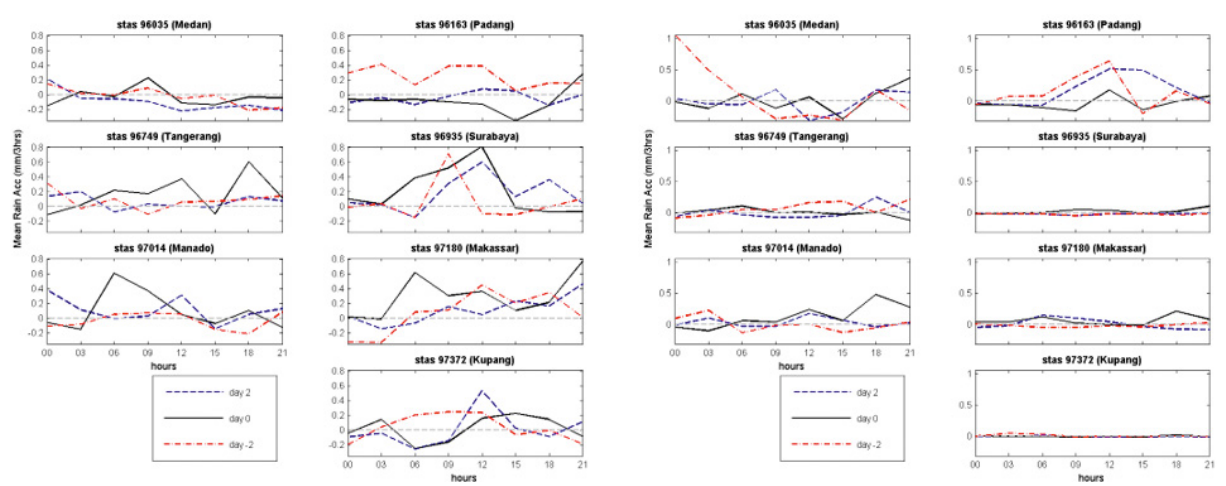

Fig. 6. A 3-hourly (time in UTC) precipitation rate related to Kelvin wave propagation for each day lags (see legend) at seven observation stations as shown in Figure 2, for DJF (left) and JAS (right)
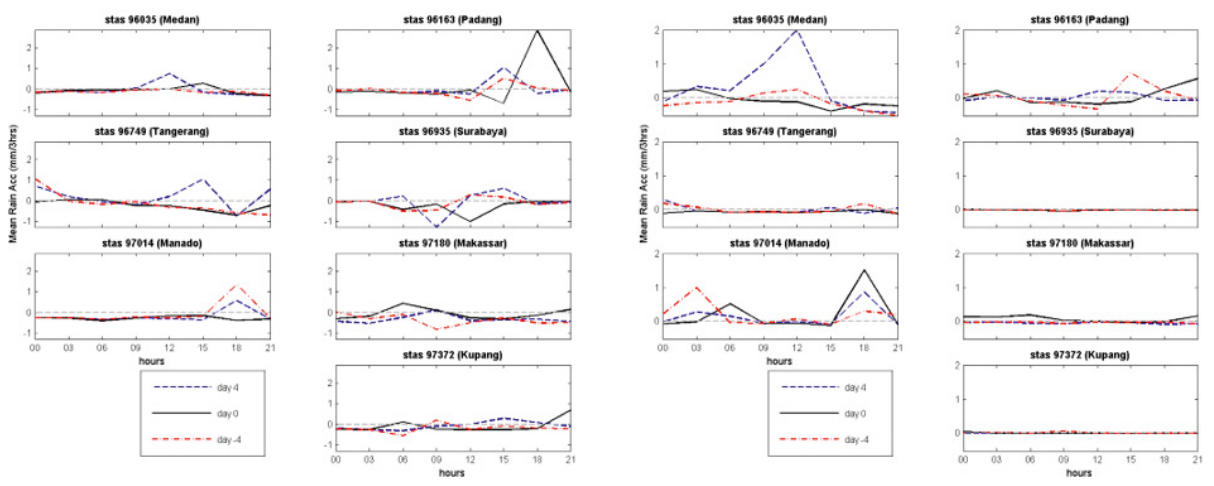

Fig. 7. A 3-hourly (time in UTC) precipitation rate related to ER wave propagation for each day lags (see legend) at seven observation stations as shown in Figure 2, for DJF (left) and JAS (right)
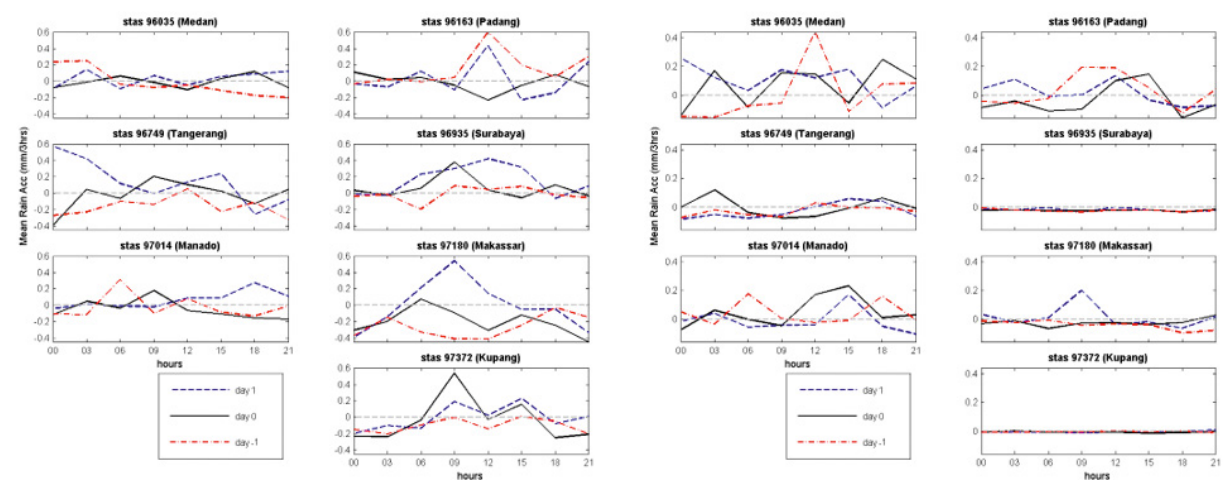

Fig. 8. A 3-hourly (time in UTC) precipitation rate related to MRG wave propagation for each day lags (see legend) at seven observation stations as shown in Figure 2, for DJF (left) and JAS (right)

DJF, except in Medan, Padang, and Kupang. This could be as result of the propagation of the Kelvin wave, where it reaches Medan and Padang at day -2 and Kupang at day +2 . A clear sky in the morning (00-03Z) exhibited in Tangerang, Surabaya, Manado, and Makassar later showed intensified rain during the afternoon (06Z) and through to the subsequent early morning (21Z), indicating a strong local convection coupled with a Kelvin wave over these locations during DJF. On the other hand, a slight positive local precipitation anomaly at all stations except Medan, Padang, and Manado, follows the positive perturbation area of the Kelvin wave during JAS (Fig. 6; right). A clear morning sky was only observed in Padang during the whole study period, with similarly clear skies at Manado at day 0 and in the afternoon at Medan seems to be clear during the afternoon. Rain was observed at Medan from the early morning up to early afternoon for almost all the intervals during JAS. However, a lack of significant positive anomaly on day 0 for those three locations during JAS reveals that the connection between Kelvin waves and local factors are dominant during WNP monsoon phase, rather than during AU monsoon phase over Indonesia.

Meanwhile, a predominant negative local precipitation anomaly at day 0 coincides with ER wave propagation during DJF and a slightly positive anomaly at day 0 during JAS (Fig. 7), indicating there is no connection between local factors and ER 

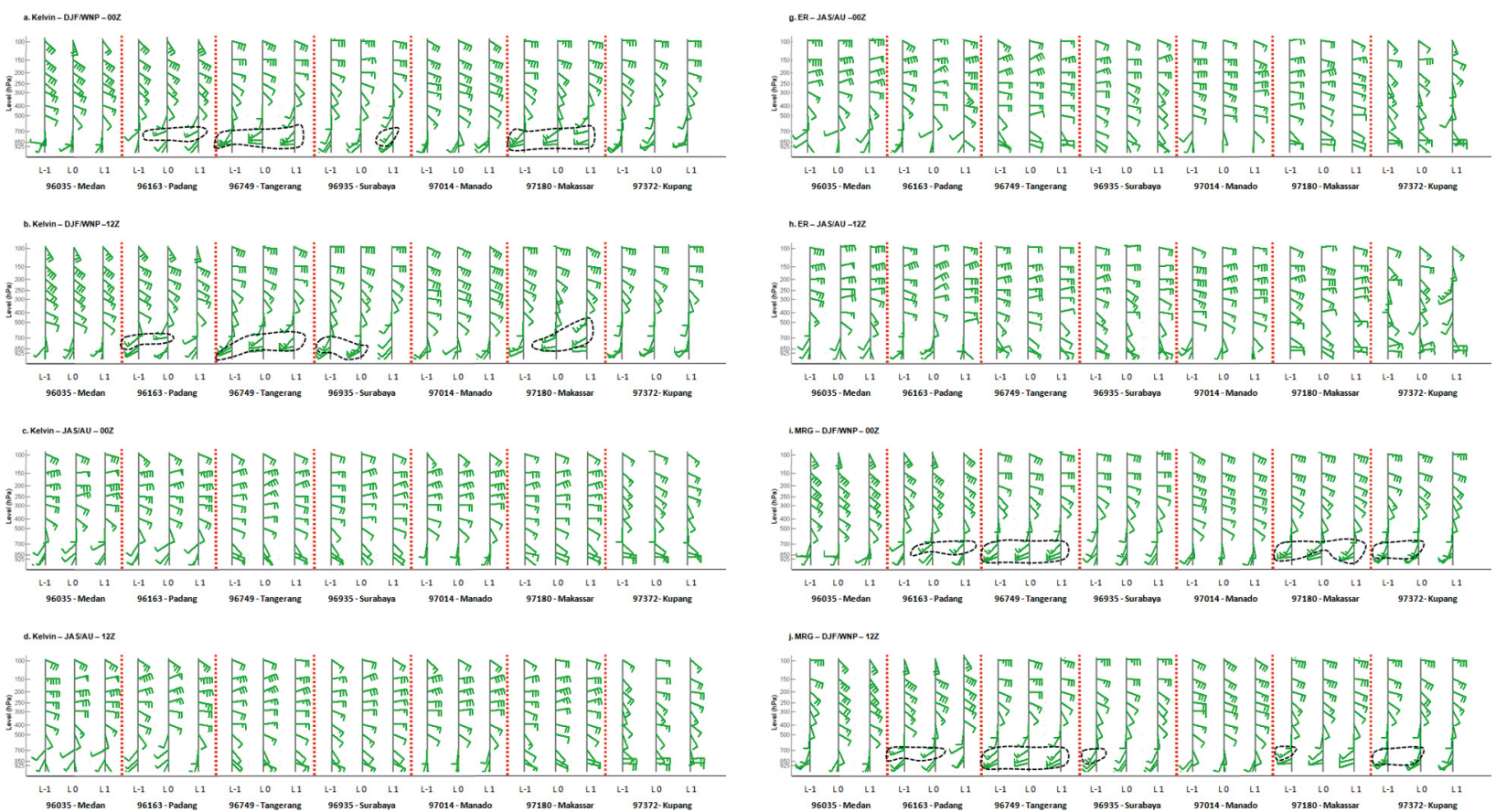

C.ER- D.FMNP - 002
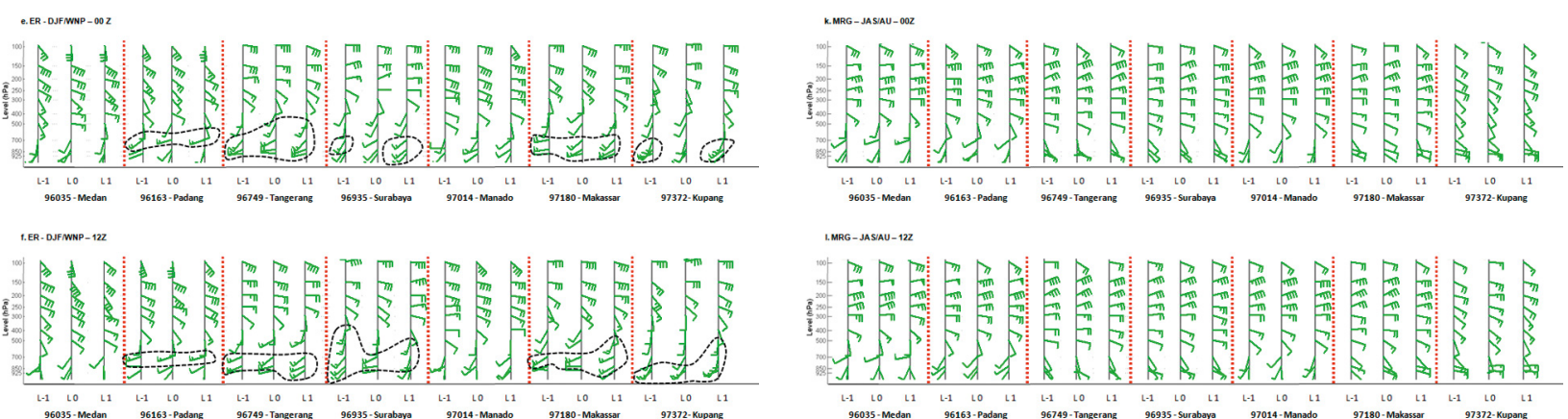

Fig. 9. Multi-level wind profiles from seven observation stations as shown in Figure 2; each lag (characterized by the hPA range on the horizontal axis) refers to the day lag for each wave, as depicted in Figure 3-8; Kelvin waves are plotted for DJF-WNP monsoon phase at $00 Z$ (a) and at $12 Z$ (b) and for JAS-AU monsoon phase at $00 Z$ (c) and at $12 Z$ (d); ER wave are plotted for DJF-WNP monsoon phase at $00 Z$ (e) and at $12 Z$ (f) and for JAS-AU monsoon phase at $00 Z$ (g) and at $12 Z$ (h); MRG waves are plotted for DJF-WNP monsoon phase at OOZ (i) and at $12 Z$ (j) and for JAS-AU monsoon phase at 00Z (k) and at $12 \mathrm{Z}$ (I); note that significant multilevel wind at >20 knots for the DJF-WNP monsoon phase and >10 knots for the JAS-ASU monsoon phase are indicated by a dashed black contour lines

waves during both monsoon phases. The distinctive significant positive anomaly which occurred in Padang during DJF, as well as anomalies in Medan and Manado during JAS can be discounted due to its incoherency with the positive perturbation area (Fig. 4). Overall, results suggest there is no local-ER connection over Indonesia related to an extreme WNP and AU monsoon phase.

A lower rate of local precipitation is shown for MRG waves for both WNP and AU monsoon phases (Fig. 8), compared with those of Kelvin and ER waves. However, a peak positive anomaly in Makassar at day +1 during DJF, and in Manado at day 0 during JAS, coincides with the positive MRG perturbation area (Fig. 5), which confirms a relationship between local factors and MRG waves, even though anomalies are less extreme (cf. Horin- ouchi 2012). At these two locations, convective rains occur during the afternoon (09Z) and evening (15Z) for Makassar during DJF and Manado during JAS, respectively. An apparent positive anomaly at other locations could be disregarded due to their inconsistency with MRG positive perturbations (Fig. 5). Hence, similar to ER waves, there is a less significant link between MRG waves and local factors which regulate convection over Indonesia, with exceptions in Makassar during the WNP monsoon phase and in Manado during the $\mathrm{AU}$ monsoon phase.

Local atmospheric dynamics exhibits only a slight divergence in wind direction between the morning (00Z) and the evening (12Z) (Fig. 9). Thus, climatological multi-level wind is primarily controlled by global scale phenomena rather than a local scale factors which exhibit daily variability.
From Figure 9 (a-l), significant ( $>10$ knots) low-level (up to $700 \mathrm{hPa}$ ) westerly winds are observed during the WNP monsoon phase for almost all locations, while a lower magnitude of westerly wind remains only over the western part of Indonesia during the $\mathrm{AU}$ monsoon phase. Figure 9 (a-d) indicates that low-level westerly winds that are particularly apparent during DJF follow significant precipitation patterns within Kelvin wave envelopes (see Fig. 3), which is in agreement with the previous finding of Yang et al. (2006). Tangerang, Surabaya and Makassar exhibit significant low-level westerly winds which coincide with significant precipitation during the WNP monsoon phase. Even though there is quite a strong westerly wind during DFJ over Padang at 00 and $12 \mathrm{Z}$, the convection cluster and Kelvin positive perturbation area do not follow 
this condition. An absence of significant westerly wind during JAS, except in Padang where a weak westerly wind follows convection, indicates local factors have little impact on vertical interferences for Kelvin waves at almost all locations in Indonesia during the AU monsoon phase.

Unlike Kelvin waves, a significant westerly wind observed over almost all locations during DJF indicates a weak connection between ER waves and local factors, due to the inconsistency in rainfall anomalies (Fig. 7). A strong westerly wind during DJF and easterly wind during JAS reveals that the monsoon controls weather conditions in Indonesia (Ramage 1971) rather than ER waves. The other reason is due to its off-equatorial center, which drives the ER signal away from the near-equatorial regions (cf. Kiladis, Wheeler 1995; Lubis, Jacobi 2014). With the exception of a significant westerly wind which is coupled with a positive local precipitation anomaly and an MRG wave (Fig. 8) in Makassar at day +1 during DJF, there is a lack of significant connection at almost all other locations, indicating that there is a less significant connection between local factors and MRG waves over almost all of Indonesia, as previously suggested by Kiladis et al. (2009).

\section{SUMMARY}

The connection between local factors and CCEW, particularly the contribution of local factors on CCEW behavior in the MC region has been assessed in this study. Significant precipitation which is linked to Kelvin wave propagation, suggests that this type of CCEW profoundly controls the weather conditions in Indonesia, particularly during DJF, compared with ER and MRG waves. This is supported by local convection during the afternoon and through to the evening in Tangerang, Surabaya and Makassar, which is linked to Kelvin wave propagation during an extreme WNP monsoon phase. The only exception to this occurs at Makassar, where local convection is associated with an MRG wave at day +1 during an extreme WNP monsoon phase.

Furthermore, low-level westerly winds associated with convection within CCEW envelopes are significant for Kelvin waves during an extreme WNP monsoon phase, while absent for ER and MRG waves, with the exception of the MRG wave in Makassar during an extreme WNP monsoon phase. These results suggest that although Kelvin waves are known to be a global scale phenomenon, their influence on convection is significantly connected to local scale factors, particularly during an extreme WNP monsoon phase over the region of Indonesia. A lack of relationship shown by ER and MRG waves with local factors during both extreme WNP and AU monsoon phases (except for the MRG wave in Makassar during an extreme WNP monsoon phase), suggest that these waves are insufficient in intensifying convection in the region of Indonesia, related to Asian-Australian monsoon. Further study with more complex datasets with greater spatial coverage is required to ascertain more detail on local-CCEW relationships, particularly over the eastern part of the Indonesian region.

\section{ACKNOWLEDGEMENT}

This research is supported by the National Aeronautics and Space Administration (NASA)-Goddard Earth Sciences Data and Information Services Center (GES DISC) for TRMM 3B42 V7 dataset, the European Centre for Medium-Range Weather Forecasts (ECMWF) for ERA-Interim reanalysis dataset, and the Indonesian Meteorological Climatological and Geophysical Agency (BMKG) for observational sounding data. Authors would like to thank the Head of the Indonesian Meteorological Climatological and Geophysical Agency (BMKG) for the full scholarship in Gadjah Mada University (UGM), Faculty of Geography, as well as to the Head of the Education and Training Center (Pusdiklat BMKG). Authors are also very grateful to Mr. George Kiladis (NOAA) for allowing the adaptation of WK99 method in this study.

\section{REFERENCES}

- Giarno, Hadi M.P., Suprayogi S., Murti S.H., 2018, Distribution of accuracy of TRMM daily rainfall in Makassar Strait, Indonesian Journal of Spatial and Regional Analysis. 32 (1), 38-52, DOI: 10.23917/forgeo.v32i1.5774

- Gill A.E., 1982, Atmosphere - Ocean Dynamics, Academic Press, 662 pp.

- Horinouchi T., 2012, Modulation of seasonal precipitation over the tropical western/central Pacific by convectively coupled mixed Rossby-gravity waves, Journal of Atmospheric Sciences, 70 (20), 600-606, DOI: 10.1175/JAS-D-12-0283.1

- Kikuchi K., Kiladis G.N., Dias J., Nasuno T., 2017, Convectively coupled equatorial waves within the MJO during CINDY/DYNAMO: slow Kelvin waves as building blocks, Climate Dynamics, 50, 4211-4230, DOI: 10.1007/s00382-017-3869-5

- Kiladis G.N., dan Wheeler M.C., 1995, Horizontal and vertical structure of observed tropospheric equatorial Rossby waves, Journal of Geophysics Research - Atmospheres, 100 (D11), 22981-22997, DOI: 10.1029/95JD02415

- Kiladis G.N., Wheeler M.C., Haertel P.T., Straub K.H., Roundy P.E., 2009, Convectively couple equatorial waves, Reviews of Geophysics, 47 (2), DOI: 10.1029/2008RG000266

- Liebmann B., dan Hendon H.H., 1990, Synoptic-scale disturbances near the equator, Journal of Atmospheric Sciences, 47 (12), 1463-1479, DOI: 10.1175/1520-0469(1990)047<1463:SSDNTE>2.0 $\mathrm{CO} ; 2$

- Lubis S.W., Jacobi C., 2014, The modulating influence of convectively coupled equatorial waves (CCEWs) on the variability of tropical precipitation, International Journal of Climatology, 35 (7), 1465-1483, DOI: 10.1002/joc.4069

- Matsuno T., 1966, Quasi-geostrophic motions in the equatorial area, Journal of the Meteorological Society of Japan, 44 (1), 25-43, DOI: 10.2151/ jmsj1965.44.1_25

- Ramage C.S., 1971, Monsoon meteorology, Academic Press, New York-London, 296 pp.

- Takayabu Y.N., Nitta T.S., 1993, 3-5 day period disturbances coupled with convection over the tropical Pacific Ocean, Journal of Meteorological Society of Japan, 71 (2), 221-246, DOI: 10.2151/ jmsj1965.71.2_221

- Wang B., Fan, Z., 1999, Choice of south Asian summer monsoon indices, Bu letin if the American Meteorological Society, 80 (4), 629-638, DOI: 10.1175/1520-0477(1999)080<0629:COSASM $>2.0 . \mathrm{CO} ; 2$

- Wang B., Liu J., Kim H.J., Webster P.J., dan Yim S.Y., 2012, Recent change of the global monsoon precipitation (1979-2008), Climate Dynamics, 39 (5), 1123-1135, DOI: 10.1007/s00382-011-1266-z

- Wheeler M., Kiladis N.G., 1999, Convectively coupled equatorial waves: analysis of clouds and temperature in the wavenumber - frequency domain, Journal of the Atmospheric Science, 56 (3), 374399, DOI: 10.1175/1520-0469(1999)056<0374:CCEWAO $>2.0 . C O ; 2$

- Wheeler M.C., McBride J. L., 2005, Australian-Indonesian monsoon, [in:] Intraseasonal variability in the atmosphere-ocean climate system, W.K.M. Lau, D.E. Waliser (eds.), Springer, Berlin, Heidelberg, 125-173, DOI: 10.1007/3-540-27250-X_5

- Yanai M., Maruyama T., 1966, Stratospheric wave disturbances over the equatorial Pacific, Journal of the Meteorologycal Society of Japan, 44 (5), 291-294, DOI: 10.2151/jmsj1965.44.5_291

- Yang G.-Y., Hoskins B., Slingo J., 2003, Convectively coupled equatorial waves: a new methodology for identifying wave structures in observational data, Journal of the Atmospheric Sciences, 60 (14), 16371654, DOI: 10.1175/1520-0469(2003)060<1637:CCEWAN>2.0.CO;2

- Yim S.Y., Wang B., Liu J., Wu Z, 2013, A comparison of regional monsoon variability using monsoon indices, Climate Dynamics, 43 (5-6), 14231437, DOI: 10.1007/s00382-013-1956-9

- Zhao C., Li T., Zhou T., 2013, Precursor signals and processes associated with MJO initiation over the tropical Indian Ocean, Journal of Climate, 26 (1), 291-307, DOI: 10.1175/JCLI-D-12-00113.1 